\title{
O MUNDO DE MARY \& MAX
}

Thais Fonseca de Andrade ${ }^{1}$

\begin{abstract}
“A vida de todos é como uma longa calçada. Algumas são bem pavimentadas, outras como a minha tem rachaduras, cascas de banana e guimbas de cigarro. A sua é como a minha, mas provavelmente com menos rachaduras. Espero que um dia nossas calçadas se encontrem". (Trecho de uma carta de Max à Maryl.
\end{abstract}

Quando assisti “Mary \& Max, uma amizade diferente", de Adam Elliot, achei que seria mais um filme bonitinho de animação, feito para crianças. Mas, não é. Para minha surpresa, este stop-motion é bem profundo, sensível e feito para adultos. É bonito observar, ao longo do filme, o encontro entre o mundo infantil, que é curioso, livre de pré-conceitos e espontâneo e o mundo adulto, que carrega em si o peso do tempo vivido, das teorias e certezas construídas a partir de uma vida já experimentada.

Este longa-metragem, que é baseado em uma história real, conta sobre a amizade entre Mary Daisy Dinkle, uma menininha australiana, de oito anos de idade e Max Jerry Horowitz, um americano de 44 anos, que mora em Nova York. Ela sonha em se casar com Mr. Earl Grey. Earl Grey é um tipo de chá, o pai de Mary trabalhava em uma fábrica que produzia saquinhos de chá. A menina, que gostaria que seu pai tivesse passado mais tempo com ela antes de morrer, adorava a palavra Earl Grey e associou-a a imagem de seu príncipe encantado. Ele mora com seus bichinhos de estimação e seu amigo invisível, Mr. Ravióli. Ambos adoram chocolate e assistem "Os Noblets", seu desenho animado preferido.

1 Psicóloga, Mestre em Ciências pela Universidade de São Paulo e Pós-Graduanda em Psicoterapia Psicanalítica pelo Instituto de Psicologia da Universidade de São Paulo. thaisandradeahotmail.com 
0 mundo de Mary é sépia, que é um tom marrom-avermelhado; o de Max é cinza escuro, que é resultado do encontro entre o branco e preto; uma mistura entre a presença e a ausência de luz. Assim como no mundo de Mary, o vermelho, mesmo que com mínima presença, também habita o mundo de Max, que tinha entre os objetivos de sua vida ter um amigo de verdade.

A narrativa transita entre esses dois mundos, essas tonalidades. 0 marrom e o cinza parecem refletir os sentimentos de inércia, solidão, desamparo e inadequação que são tão presentes na vida psíquica desses dois personagens. No entanto, Adam Elliot usa também o vermelho, que aparece colorindo o marrom de Mary (que é a sua cor favorita) e em detalhes como, por exemplo, na sua presilha de cabelo, às vezes em um anel que identifica seus humores, em seu batom, na língua de Max e em um pompom vermelho que ele usava sobre seu solidéu preto. Este era um resquício de sua cultura judaica e, segundo ele, servia apenas para "esquentar seu cérebro". 0 pompom foi um presente de Mary que ela mesma fez. Assim que ele o recebeu colocou-o sobre o solidéu.

Ao trazer o vermelho para o mundo deles, o diretor me fez pensar que, apesar das emoções acima citadas, sentimentos ligados ao amor, à criatividade e à esperança também estavam presentes nos mundos desses protagonistas. Penso que a beleza do filme Mary \& Max está na sutileza e na sensibilidade do diretor em expressar por meio das cores, da densidade das formas (o cenário e os personagens são feitos de massas de modelar), do ritmo lento da narrativa e das músicas reflexivas, o mundo interno dos personagens.

Ambos se encontram por um acaso. Um dia, Mary foi fazer compras com sua mãe, uma mulher extremamente egocêntrica, vaidosa e nada amorosa, que sofria de cleptomania e alcoolismo e, enquanto a esperava, se interessou por uma lista telefônica da cidade de Nova York porque a capa era marrom. A menina, então, a folheou e aleatoriamente escolheu um nome que a atraiu: Max Jerry Horowitz. Ela resolveu escrever para ele para convidá-lo para ser seu amigo e também para saber como os bebês nascem na América, assunto que a intrigava. Seu avô havia lhe contado que os bebês, na Austrália, são encontrados em copos de cerveja. Quando Max recebeu a carta, seu mundo escuro, estático, quase impenetrável desmantelou. Ele 
sentiu-se tão apavorado e desestruturado com a possibilidade desse contato, que levou 18 horas para conseguir se organizar internamente e responder a nova amiga.

Max é muito vulnerável em relação ao outro e intolerante a qualquer tipo de frustração vivida. Além disso, ele não consegue expressar suas emoções e nem compreende bem quando o outro as expressa. Max sente o amor, mas sofre muito para articulá-lo e, por isso, gostaria que existisse uma equação matemática para esse sentimento. Seu mundo é concreto e repetitivo, ele busca a todo custo manter sua vida simétrica e qualquer situação nova ou inesperada que acontece lhe provoca enorme desorganização psíquica e extrema ansiedade. Ele faz tratamento com um psiquiatra, figura importante em sua vida, e participa em um grupo de apoio para comedores compulsivos porque é obeso. Max é diagnosticado como portador da Síndrome de Asperger, mas não se reconhece doente, apenas diferente. Dentro desse contexto, é possível imaginar como a carta de Mary o fez sentir. 0 fato é que ele conseguiu the escrever. Talvez a inocência da menina tenha despertado a sua coragem e a vontade de ter um amigo de verdade ficou mais forte do que o medo. É o vermelho entrando em cena...

Freud em “Sobre o Narcisismo, Uma Introdução”, de 1914 diz que

\footnotetext{
"um egoísmo forte constitui uma proteção contra o adoecer, mas num último recurso, devemos começar a amar a fim de não adoecermos, e estamos destinados a cair doentes se, em consequência da frustração, formos incapazes de amar". (FREUD, 1914, p. 92).
}

Max vive no fio da navalha, sob a força de um narcisismo mortífero que mantém seu status-quo interno, que mantém a sua estrutura, que é muito frágil, em pé. Mas o que parece protetor é e não é. Ele precisa ficar isolado em seu mundo para não enlouquecer, mas a loucura é essa. A dor é essa porque ele quer o contato com o outro, mas esse mesmo contato é extremamente angustiante e terrorífico. Por isso, emociona ver que ele consegue aceitar o 
convite de Mary que, para mim, foi mais do que um convite de amizade, foi um convite à vida, à criatividade, ao amor e, claro, inevitavelmente, à dor. Então Max, ao responder a ela, aceitou correr um risco que, para ele, era um grande risco. Este recurso interno está intimamente ligado à sua capacidade amorosa e àquele narcisismo que leva à vida e não à morte².

E eles cultivam essa amizade por meio de cartas e passam a compartilhar suas histórias mais íntimas e seus questionamentos sobre temas que compreendem a existência humana. Além disso, trocam pequenos presentes, como o pompom vermelho acima mencionado, chocolates e até mesmo lágrimas. Lágrimas? Em uma das cartas Max conta para Mary que, por mais que ele tente, não consegue chorar. A menina resolve então chorar suas lágrimas e as envia para o amigo em um pequeno frasco. Max as coloca em seus olhos e em seu rosto e experimenta essa sensação. Dessa forma, por meio de um diálogo singular, vão tecendo os fios de uma grande amizade que, mesmo à distância, transita pelas diversas emoções presentes em um relacionamento bem de perto. É uma dança constante entre sentimentos que permeiam amor e dor, coragem e medo, desilusão e esperança.

E assim, os anos vão passando e eles se transformando... Mary vira mulher e Max envelhece. Nesse ínterim, ela entra na faculdade e vai estudar sobre a doença do amigo para descobrir a sua cura. Sua pesquisa vira um livro de sucesso científico que ela envia prontamente para ele. Além disso, ela se apaixona, casa, engravida e passa a viver uma vida adulta. 0 livro enviado a Max causa-lhe profundo desgosto e raiva, ele se sente traído porque não se via como um doente que precisasse de cura e rompe com Mary: arranca a letra $M$ de sua máquina de escrever e o pompom vermelho do solidéu, que durante tantos anos representou a sua presença afetuosa. Ela reconhece a sua atitude onipotente e entra em depressão, que é reforçada quando o marido a abandona. Max e Mary ficam muito tempo sem comunicação, apesar de ela ter lhe

2 Nesse parágrafo faço referência às ideias de André Green, psicanalista da linha francesa, que em seu livro "Narcisismo de vida, Narcisismo de morte", sinaliza a presença desses dois tipos de narcisismos. 0 primeiro busca a integração do eu; o segundo, negativo, tende à sua anestesia e inexistência. 
pedido desculpas. A depressão de Mary lhe desperta características negativas de identificação com a mãe, ela passa a beber, perde o interesse pela vida e quase comete suicídio. Um dia ela recebe uma carta de Max a perdoando; após um longo período de elaboração, ele se dá conta de que ela é imperfeita assim como ele. A possibilidade de amizade volta a florescer.

Um ano depois Mary, com seu filhinho no colo, finalmente vai visitar o amigo pela primeira vez. Para sua surpresa quando chega a seu apartamento, Max está morto, ele havia morrido naquela manhã. 0 que parece um final muito triste e desesperançoso, afinal eles nunca se encontram. No entanto, essa última cena traz em si uma esperança. Mary, ao chegar à casa do amigo, nota primeiramente que ele está morto, mas depois, olha ao redor da casa, e depara-se com todas as cartas que ela havia the enviado na parede, além de coisinhas que eles haviam trocado ao longo de todos esses anos, como o recipiente que guardava as suas lágrimas, ali bem perto do amigo e bem presentes na vida dele. Ela sorri, a sensação que tive foi a de que, naquele momento, Mary se sentiu feliz.

É interessante porque ambos sentiam-se incapazes de viver o amor. No entanto, em minha opinião, esta amizade incomum é uma história de amor. Penso que Mary sorriu porque, naquele momento, ela se sentiu capaz de vivê-lo, talvez ela tenha compreendido que não fracassou. Afinal, um vínculo entre duas pessoas só pode se construir a partir da capacidade amorosa de cada um. Parece que Mary, com a sua inocência infantil, pinçou essa capacidade lá nas profundezas do mundo cinzento e quase impenetrável de Max, que conseguiu sair de si e ir a sua direção.

Um dia ela arriscou e tomada pela curiosidade e pela necessidade de ter um amigo, escreveu para um estranho. Foi o vermelho agindo em seu mundo interno... Ela era uma criança, não sabia disso conscientemente, mas acho que ela estava buscando algum sentido para sua vida e parece ter descoberto a partir desse encontro. 


\section{REFERÊNCIA BIBLIOGRÁFICA:}

FREUD, Sigmund. Sobre o narcisismo: Uma introdução (1914). In: Edição Standard Brasileira das Obras Psicológicas Completas de Sigmund Freud, vol. XIV. Rio de Janeiro: Imago, 1996.

GREEN, André. Narcisismo de vida, narcisismo de morte. $1^{\circ}$ Edição. São Paulo: Escuta, 1988.

FILMOGRAFIA:

ELLIOT, Adam. Mary \& Max, uma amizade diferente. Austrália: 2009. 